\title{
The prognostic role of Sirt1 expression in solid malignancies: a meta-analysis
}

\author{
Changwen Wang ${ }^{1, *}$, Wen Yang ${ }^{1, *}$, Fang Dong ${ }^{1}$, Yawen Guo ${ }^{1}$, Jie Tan ${ }^{1}$, Shengnan \\ Ruan $^{1}$ and Tao Huang ${ }^{1}$ \\ ${ }^{1}$ Department of Breast and Thyroid Surgery, Union Hospital, Tongji Medical College, Huazhong University of Science and \\ Technology, Wuhan, China \\ *These authors contributed equally to this work \\ Correspondence to: Tao Huang, email: huangtaowh@163.com \\ Shengnan Ruan, email: ruanshengnan@yahoo.com
}

Keywords: Sirt1, solid malignancy, prognosis, meta-analysis

Received: January 21, 2017

Accepted: May 29, 2017

Published: June 15, 2017

Copyright: Wang et al. This is an open-access article distributed under the terms of the Creative Commons Attribution License 3.0 (CC BY 3.0), which permits unrestricted use, distribution, and reproduction in any medium, provided the original author and source are credited.

\section{ABSTRACT}

Although many studies have discussed the association of abnormally expressed silent information regulator 1 (Sirt1) with the prognosis of patients with a variety of solid carcinomas, they failed to agree on whether excessive Sirt1 indicates a good or poor overall survival for the patients. We conducted the current meta-analysis to illustrate the prognostic value of Sirt1 in solid malignancies. Articles published before December 2016 were searched using Pubmed and Web of Science. The studies were selected for the meta-analysis based on certain criteria. A total of 7,369 cases from 37 studies were included, in which $48.6 \%$ of the patients overexpressed Sirt1. The overall survival (OS) and clinical features, such as age and TNM stage, were analyzed using RevMan 5.3 software. Sirt1 overexpression was significantly correlated with the OS (HR: 1.52, 95\% CI: $[1.23,1.88], P=0.0001)$, especially in liver cancer (HR: 1.78, 95\% CI: $[1.46,2.18], P<0.00001)$ and lung cancer (HR: $1.80,95 \%$ CI: [1.06, $3.05], P=0.03$ ), which suggested that the overexpression of Sirt1 indicates poor prognosis of patients with solid cancers.

\section{INTRODUCTION}

The increase in cancer prevalence and mortality and its impact on social economy have drawn enormous attention towards investigations into the occurrence, development and metastasis of cancer [1]. A large number of cell signaling pathways have been discovered and studied, and accumulating evidence has shown that epigenetic regulation of gene expression contributes significantly to solid malignancy [2]. Aberrant activation of key epigenetic pathways, including Sirt1 signaling, contributes to carcinogenesis in a variety of tumors, suggesting a potential therapeutic target for future treatments [3].

Sirt1, a proto member of the sirtuin family, is an $\mathrm{NAD}^{+}$-dependent histone deacetylase. Sirt1 modifies histones and non-histone proteins through deacetylation
[4]. Sirt1 plays pivotal roles in a variety of physiological processes, such as cell metabolism, proliferation, senescence, apoptosis, and tumorigenesis [3, 4]. It exercises its functions through p53 [5], FoxO1 [6], NF- $\kappa \mathrm{B}$ [7] and other signaling pathways. Sirt1, because of its tumorigenic characteristics, can be targeted for therapy, which may provide a longer lifespan and better quality of life for cancer patients. Interestingly, Sirt1 seems to have dual roles in cancer. Sirt1 promotes tumorigenesis by boosting cell survival under stress conditions but facilitates uncontrolled cell proliferation, and additionally, it can defend against carcinomas by increasing genomic stability and limiting cellular replicative lifespan [8]. Additionally, Sirt1 expression is increased in ovarian cancer [9] and gastric cancer [10], whereas it is reduced in liver cancer and breast cancer [11]. Therefore, it remains controversial whether Sirt1 overexpression indicates 
a good or poor prognosis. Although the majority of the evidence shows that overexpressed Sirt1 has a negative prognostic effect on cancer patients, Jung et al. [12] failed to draw the same conclusion, and their data suggested that higher Sirt1 expression resulted in a better survival status. Consequently, the clinical significance of SIRT1 in cancers is complex and requires further investigation. Therefore, in the present study, we conducted an exhaustive meta-analysis and subgroup analyses to understand the prognostic effects of Sirt1 overexpression in solid malignancies, with the aim to provide evidence for improved targeted regimens.

\section{RESULTS}

\section{Eligible studies}

Most of the studies found during the initial search were excluded based on the selection criteria such as inappropriate article type, replicated data or insufficient original information. Eventually, 37 qualified studies containing 7,369 cases were included for analyses. Figure 1 shows the selection workflow of eligible studies for our meta-analysis.

\section{Demographic characteristics of the included studies}

Among the 37 studies, the majority (15) of them were conducted in China, followed by Korea $(n=13)$ and other countries. The majority of the studies were based on breast cancer $(n=8)$, followed by colorectal carcinoma, hepatocellular carcinoma, gastric cancer
( $n=5$, respectively), lung cancer $(n=4)$, and other types of solid carcinoma. The sample sizes ranged from 40 to 557, with a median of 144 patients. Among the 37 studies, 34 studies described the correlation between overall survival and Sirtl expression, 9 trials demonstrated the relationship between disease-free survival and Sirt1 expression, 6 studies discussed relapse-free survival and Sirt1 expression, and 3 articles studied the correlation of cancer-specific survival and abnormal expression of Sirt1. Other details and features were recorded and are summarized in Table 1. All the eligible entries scored higher than six by NOS, suggesting a high methodological quality across all studies.

\section{Correlation of Sirt1 expression with the overall survival and subgroup analyses}

Thirty-four trials offered data on the correlation between the overall survival and Sirt1 expression. Our calculations showed that higher Sirt1 expression indicated an unfavorable overall survival for solid malignancies (HR: 1.52, 95\% CI: [1.23, 1.88], $P=0.0001$, Figure 2). Because of the significant heterogeneity $\left(I^{2}=74 \%\right)$, we applied a random-effects model for the statistical analysis. To determine possible sources of heterogeneity among studies, we grouped the original articles for subgroup analyses, based on several factors. In the cancer subgroup, Sirt1 overexpression was associated with a worse overall survival in liver cancer $(n=5, \mathrm{HR}: 1.78,95 \%$ CI: [1.46, 2.18], $P<0.00001, I^{2}=0 \%$, Figure 3 ) and lung cancer $\left(n=4\right.$, HR: $1.80,95 \%$ CI: [1.06, 3.05], $P=0.03, I^{2}=37 \%$, Figure 4), whereas Sirt1 overexpression was not correlated with the overall survival in breast cancer $(n=7, \mathrm{HR}: 1.25$,

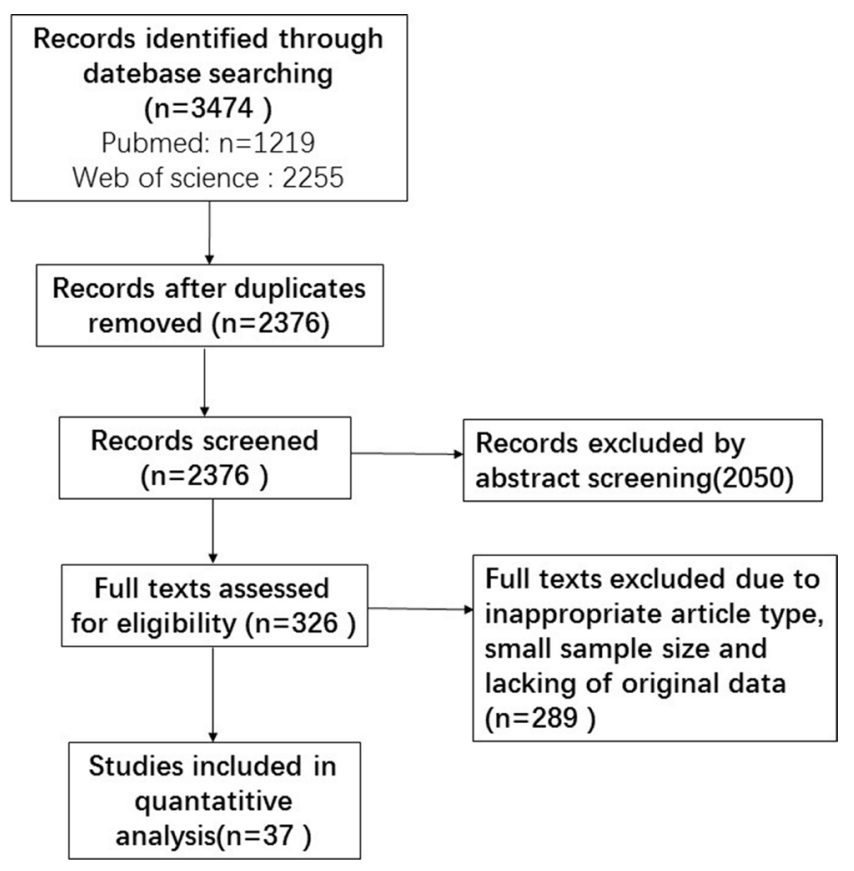

Figure 1: Flow chart of the selection for the meta-analysis. 
Table 1: Demographic information of included studies

\begin{tabular}{|c|c|c|c|c|c|c|c|c|c|}
\hline Reference & Country & Cancer type & No. & Male/Femaleale & TNM Stagee & Sirt1 high (+) & Sirt1 low & $\begin{array}{c}\text { Follow-up } \\
\text { range months }\end{array}$ & NOS score \\
\hline Zhang 2016 [13] & China & breast cancer & 149 & All female & I-III & 68 & 81 & NA & 7 \\
\hline Chen 2014 [14] & China & colorectal adenocarcinoma & 102 & $56 / 46$ & II-IV & 44 & 58 & NA & 7 \\
\hline Jang 2012 [15] & South Korea & colorectal adenocarcinoma & 497 & $281 / 216$ & I-IV & 208 & 289 & NA & 8 \\
\hline Jung 2013 [12] & South Korea & colorectal adenocarcinoma & 349 & $208 / 141$ & I-IV & 235 & 114 & NA & 8 \\
\hline Cheng 2016 [16] & China & colorectal adenocarcinoma & 90 & $47 / 43$ & I-IV & 37 & 53 & NA & 7 \\
\hline He 2016 [17] & China & esophageal squamous cell carcinoma & 86 & $64 / 22$ & I-III & 54 & 32 & NA & 7 \\
\hline Chen 2014a [18] & China & esophageal squamous cell carcinoma & 206 & $152 / 54$ & NA & 95 & 111 & $5-86$ & 7 \\
\hline Zhang 2013 [19] & China & gastroesophageal junction cancer & 90 & NA & NA & 46 & 44 & NA & 7 \\
\hline Cha 2009 [10] & South Korea & gastric carcinoma & 177 & $135 / 42$ & I-IV & 130 & 47 & NA & 7 \\
\hline Cao 2014 [20] & China & breast cancer & 122 & All female & I-IV & 94 & 28 & $2-161$ & 7 \\
\hline Kang 2012 [21] & South Korea & gastric carcinoma & 452 & $309 / 143$ & I-IV & 255 & 197 & NA & 7 \\
\hline Feng 2011 [22] & China & gastric carcinoma & 90 & NA & NA & 46 & 44 & NA & 7 \\
\hline Noguchi 2014 [23] & Japan & gastric carcinoma & 557 & $391 / 166$ & I-IV & 345 & 212 & $6-142$ & 8 \\
\hline Hao 2014 [24] & China & hepatocellular carcinoma & 99 & $89 / 10$ & I-IV & 76 & 23 & NA & 6 \\
\hline Song 2014 [25] & China & hepatocellular carcinoma & 300 & $267 / 33$ & I-IV & 145 & 155 & $3-83$ & 7 \\
\hline Jang 2012 [18] & South Korea & hepatocellular carcinoma & 154 & $132 / 22$ & I-IV & 55 & 99 & NA & 7 \\
\hline Li 2016 [26] & China & hepatocellular carcinoma & 72 & $65 / 7$ & I-III & 41 & 31 & NA & 6 \\
\hline Chen 2012 [27] & China & hepatocellular carcinoma & 172 & $142 / 30$ & NA & 95 & 77 & $45-236$ & 7 \\
\hline Noguchi 2013 [28] & Japan & head and neck squamous cell carcinoma & 437 & $356 / 81$ & NA & 348 & 89 & $1-174$ & 8 \\
\hline Chung 2015 [29] & South Korea & breast cancer & 427 & All female & NA & 227 & 150 & NA & 7 \\
\hline Yu 2013 [30] & China & laryngeal and hypopharyngeal carcinomas & 46 & NA & NA & 17 & 29 & NA & 7 \\
\hline Grbesa 2015 [31] & Spain & lung cancer & 105 & $93 / 12$ & NA & 52 & 53 & NA & 7 \\
\hline Noh 2013 [32] & South Korea & lung cancer & 144 & $82 / 62$ & NA & 75 & & $40-136$ & 7 \\
\hline Li 2015 [33] & China & lung cancer & 75 & $39 / 36$ & I-IV & 56 & 19 & NA & 7 \\
\hline Shin 2016 [34] & South Korea & ovarian cancer & 45 & NA & NA & 16 & 29 & NA & 6 \\
\hline Lee 2010 [35] & South Korea & breast cancer & 122 & All female & NA & 82 & 40 & NA & 7 \\
\hline Mvunta 2016 [36] & Japan & ovarian cancer & 68 & All female & NA & 11 & 57 & NA & 7 \\
\hline Stenzinger 2013 [37] & Germany & pancreatic cancer & 113 & NA & NA & 32 & 81 & NA & 7 \\
\hline Noh 2013 [38] & South Korea & renal cell carcinoma & 200 & $140 / 60$ & I-IV & 119 & 81 & NA & 7 \\
\hline Batra 2016 [39] & India & retinoblastoma & 94 & $62 / 32$ & NA & 49 & 45 & NA & 6 \\
\hline Kim 2013 [40] & South Korea & soft tissue sarcomas & 104 & $59 / 45$ & NA & 74 & 30 & NA & 7 \\
\hline Benard 2015 [41] & Dutch & colorectal adenocarcinoma & 254 & $128 / 126$ & I-III & NA & NA & NA & 6 \\
\hline Chung 2016 [42] & South Korea & breast cancer & 344 & All female & NA & 146 & 198 & NA & 8 \\
\hline Jin 2016 [43] & South Korea & breast cancer & 319 & All female & I-III & 107 & 212 & NA & 7 \\
\hline Wu 2012 [44] & China & breast cancer & 134 & All female & NA & 72 & 62 & NA & 6 \\
\hline Gharabaghi 2016 [45] & Iran & lung cancer & 40 & $23 / 17$ & NA & 27 & 13 & NA & 6 \\
\hline Derr 2014 [46] & Dutch & breast cancer & 460 & All female & I-III & NA & NA & $2-330$ & 7 \\
\hline
\end{tabular}

NOS: Newcastle-Ottawa Scale.

NA: not available.

95\% CI: $[0.70,2.22], P=0.46, I^{2}=75 \%$, Supplementary Figure 1), colorectal carcinoma ( $n=5$, HR: $1.12,95 \%$ CI: [0.66,1.89], $P=0.67, P^{2}=81 \%$, Supplementary Figure 2), and gastric carcinoma ( $n=4$, HR: $1.44,95 \% \mathrm{CI}$ : $[0.60,3.45], P=0.41, P^{2}=81 \%$, Supplementary Figure 3). When the studies were sub grouped based on TNM clinical stages, we found several studies that discussed pre-terminal stages (TNM I-III) $(n=6$, HR: $1.16,95 \%$
CI: [0.98, 1.38], $P=0.09, I^{2}=8 \%$, Supplementary Figure 4), and only one study [14] that included advanced TNM stages (II-IV) with HR: 3.51, 95\% CI: $(1.68,7.33)$. Moreover, in studies that covered all stages (TNM I-IV), overexpression of Sirt1 suggested a poorer overall outcome $(n=12$, HR: $1.35,95 \%$ CI: [0.87, 2.11], $P=0.18, I^{2}=86 \%$, Supplementary Figure 5). Two studies evaluated the nuclear and cytoplasmic Sirt1 expressions 


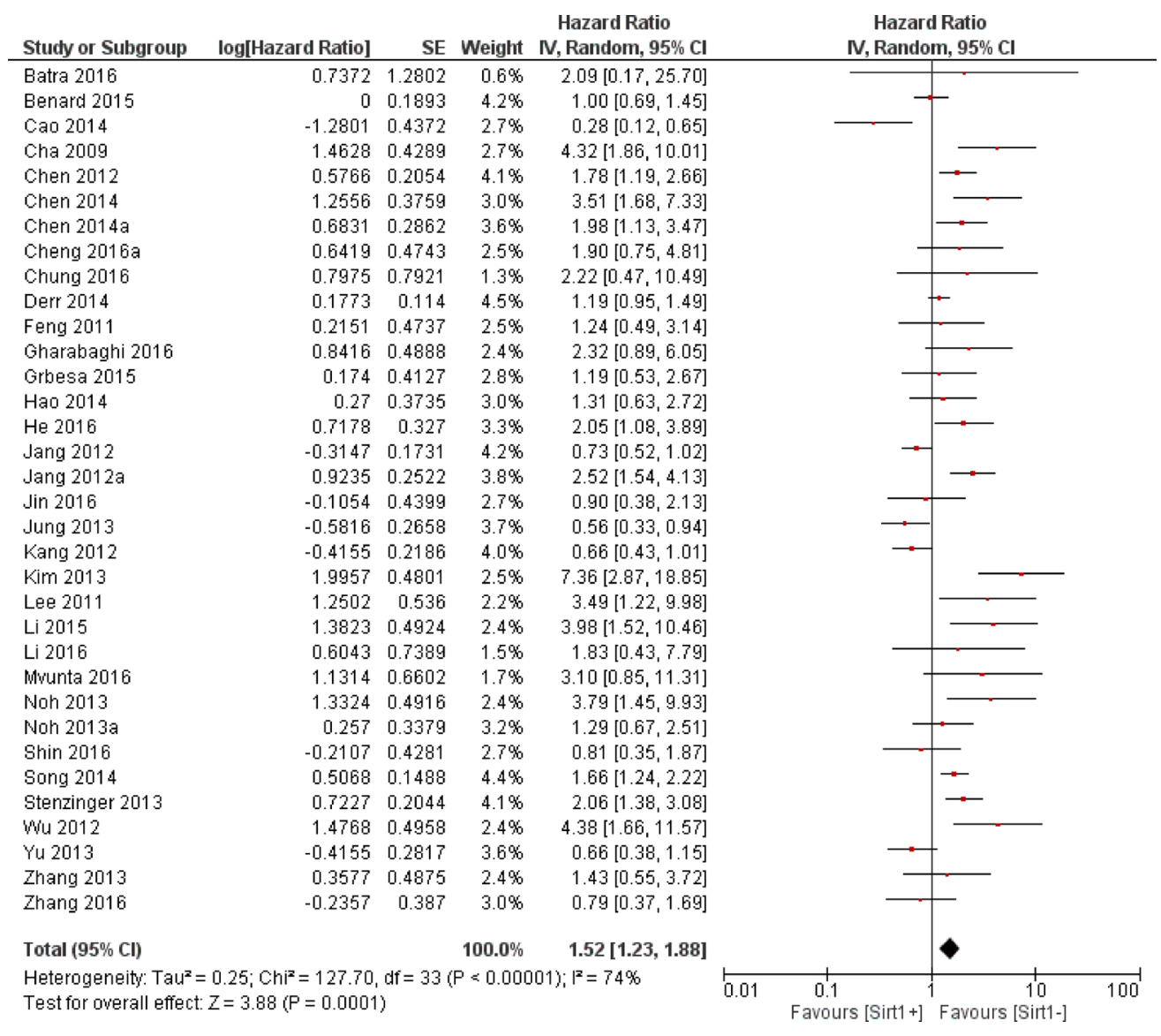

Figure 2: The correlation between Sirt1 expression and overall survival in solid malignancies.

\begin{tabular}{|c|c|c|c|c|c|c|c|c|}
\hline Study or Subgroup & log[Hazard Ratio] & SE & Weight & $\begin{array}{l}\text { Hazard Ratio } \\
\text { IV, Fixed, } 95 \% \mathrm{Cl}\end{array}$ & & $\begin{array}{r}\text { Hazard } \\
\text { IV, Fixed }\end{array}$ & $\begin{array}{l}\text { Ratio } \\
\text { I, } 95 \% \mathrm{Cl}\end{array}$ & \\
\hline Chen 2012 & 0.5766 & 0.2054 & $25.3 \%$ & $1.78[1.19,2.66]$ & & & $\rightarrow-$ & \\
\hline $\mathrm{Hao} 2014$ & 0.27 & 0.3735 & $7.7 \%$ & $1.31[0.63,2.72]$ & & & & \\
\hline Jang $2012 a$ & 0.9235 & 0.2522 & $16.8 \%$ & $2.52[1.54,4.13]$ & & & $\longrightarrow$ & \\
\hline Li 2016 & 0.6043 & 0.7389 & $2.0 \%$ & $1.83[0.43,7.79]$ & & & & \\
\hline Song 2014 & 0.5068 & 0.1488 & $48.3 \%$ & $1.66[1.24,2.22]$ & & & -1 & \\
\hline Total (95\% Cl) & & & $100.0 \%$ & $1.78[1.46,2.18]$ & & & & \\
\hline \multicolumn{5}{|c|}{$\begin{array}{l}\text { Heterogeneity: Chi }=2.79, \mathrm{df}=4(\mathrm{P}=0.59) ; I^{2}=0 \% \\
\text { Test for owerall effect: } Z=5.59(\mathrm{P}<0.00001)\end{array}$} & 0.01 & $\begin{array}{c}0.1 \\
\text { Favours [Sirt1+] }\end{array}$ & $\begin{array}{c}10 \\
\text { Favours [Sirt1-] }\end{array}$ & 100 \\
\hline
\end{tabular}

Figure 3: The correlation between Sirt1 expression and overall survival of liver cancer.

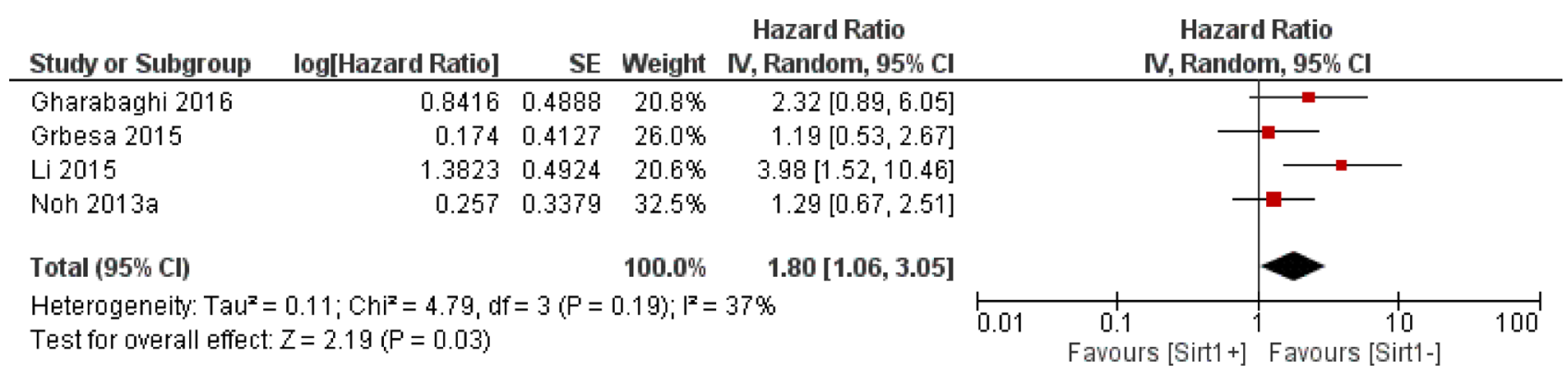

Figure 4: The correlation between Sirt1 expression and overall survival of lung cancer. 
separately, with distinctive results. One article showed that overexpression of Sirt1 in the cytoplasm is indicative of a good prognosis $(P<0.005)$, whereas another suggested that increased expression of Sirt1 significantly correlated with poor patient survival $(\mathrm{HR}=2.617, P=0.019)$. The remaining studies detected the nuclear expression of Sirt1 expression $(n=17$, HR: $1.56,95 \%$ CI: [1.15, 2.12], $\left.P=0.004, I^{2}=80 \%\right)$.

\section{Correlation of Sirt1 expression with disease- free survival, relapse-free survival and cancer- specific survival}

Unfortunately, our analysis failed to conclude the significance between increased Sirt1 expression and relapse-free survival (RFS, $n=6$, HR: $1.58,95 \% \mathrm{CI}$ : $[0.97,2.60], P=0.07, I^{2}=84 \%$, Supplementary Figure 6), disease-free survival (DFS, $n=9$, HR: 1.23 , 95\% CI: $[0.88,1.73], P=0.22, I^{2}=71 \%$, Supplementary Figure 7) or cancer-specific survival (CSS, $n=3$, HR: $1.40,95 \% \mathrm{CI}$ : $[0.60,3.30], P=0.44, I^{2}=89 \%$, Supplementary Figure 8) among solid malignancies.

\section{Sensitivity analysis}

Excluding studies about breast cancer $(n=27$, HR: $1.60,95 \%$ CI: [1.26, 2.04], $P=0.0001, I^{2}=74 \%$ ), colorectal cancer $(n=29, \mathrm{HR}: 1.62,95 \% \mathrm{CI}$ : [1.29, 2.03], $\left.P<0.0001, I^{2}=70 \%\right)$, and gastric cancer $(n=30$, HR: 1.54, 95\% CI: $[1.23,1.92], P=0.0001, I^{2}=74 \%$ ) had no substantial impact on the outcome of overall survival; however, a large heterogeneity was consistently observed.

Eliminating studies that scored 6 on the NOS scale did not alter the unfavorable prognostic effect of Sirt1 overexpression on the overall survival in patients with solid malignancies $(n=27$, HR: $1.53,95 \% \mathrm{CI}$ : $[1.20,1.94], P=0.0006, I^{2}=78 \%$ ).

\section{Publication bias}

We used funnel plots to visualize publication bias. (Figure 5).

\section{DISCUSSION}

The dual nature of Sirt1 in cancer remains a controversy and could be a consequence of several factors including its different expression levels in various types of carcinoma, its subcellular location, and diverse downstream substrates. Earlier studies predominately reported nuclear Sirt1 expression levels, whereas more recent studies have included cytoplasmic Sirt1 expression levels. It has been proposed that subcellular localization may account for the dual roles of SIRT1 in normal versus cancer cells [47]. One study suggested that the cytoplasmic SIRT1 originates in the nucleus and plays a role in enhancing caspase-dependent apoptosis [48]. All these studies suggested that cytoplasmic expression of Sirt1 is a worse indicator of poor prognosis in cancer patients than the nuclear expression of Sirt1. However, of all the included studies, there were only two articles that discussed the relationship between Sirt1 cytoplasmic expression and patient survival, and regardless, the two studies failed to draw the same conclusion. This inconsistency could be because of different scoring criteria or differing protocols, and therefore, additional studies that precisely illuminate the impact of cytoplasmic Sirt1 expression are needed.

Although an overwhelming number of studies have established evidence that indicates an unfavorable impact of Sirt1 overexpression on patient prognosis in a wide range of carcinomas, several recent investigations revealed a superior survival duration in cases with abnormal expressions of Sirt1. The exact cause for this inconsistency is unknown. Thus, from a clinical

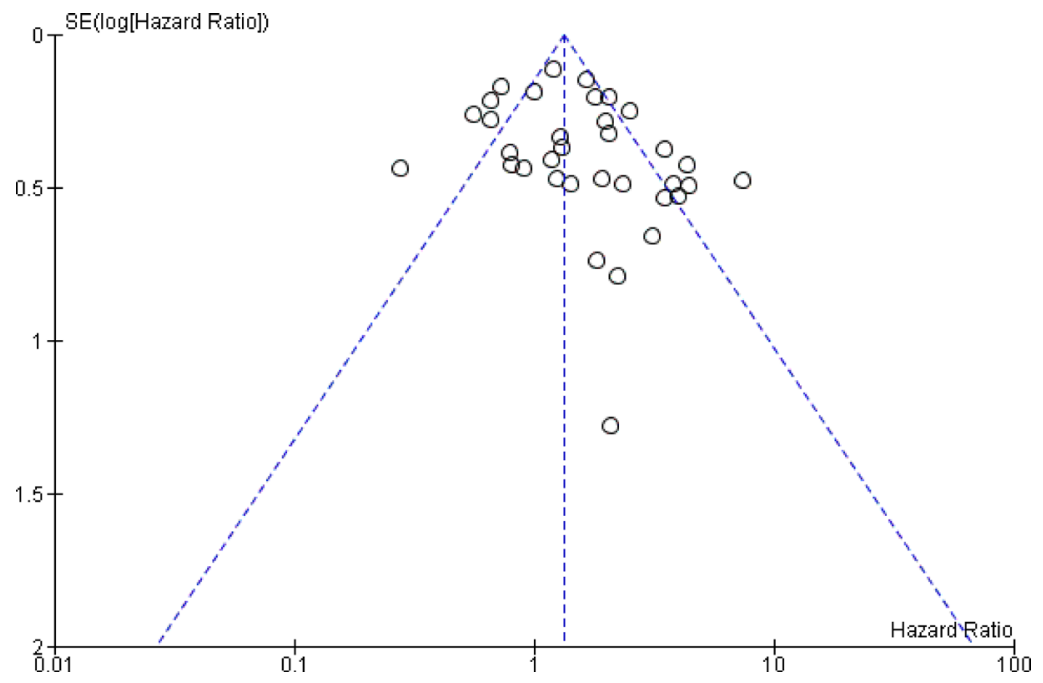

Figure 5: The funnel plots for this meta-analysis. 
perspective, the significance of Sirt1 in patient survival is unknown due to the lack of convincing evidence, and therefore, a comprehensive study is urgently needed.

Based on our knowledge, our study is the first and most versatile meta-analysis that systematically elucidates the prognostic role of Sirt1 overexpression in solid malignancies. Altogether, the results of our analyses strongly support the current mainstream point that Sirt1 redundancy was significantly correlated with patient overall survival in carcinomas. Furthermore, this unfavorable prognostic impact was independent of TNM stages. However, our quantitative analysis found that Sirt1 overexpression was not associated with patient survival in breast cancer, colorectal cancer, and gastric cancer, which was inconsistent with a majority of previous findings, and this contradiction could result from the data collection process. Some of the included study data were acquired from figures in the articles because of a lack of individual patient data. It is also worth mentioning that our subgroup analyses of the correlations between abnormal Sirt1 expression and breast cancer or gastric cancer did not lead to the same conclusions as the meta-analysis $[49,50]$. These inconsistencies originated from the differences in literature selection criteria: we excluded data that were not published in English and those from geo database in cases of data duplication.

Apart from the interesting results, there are some limitations to this quantitative meta-analysis. First, the heterogeneity among the studies remained, despite the usage of a random-effects model and subgroup analyses. The heterogeneity could have resulted in outcome bias. Second, we barely explored the correlation between Sirt1 overexpression and patient survival in terms of clinical parameters. Other elements that may contribute to the heterogeneity, such as pathological grade, body mass index, and mean age, were not analyzed due to the lack of sufficient data. Finally, because of a shortage of original individual patient data, we performed a quantitative metaanalysis based mostly on secondary data, which could lead to inaccurate results.

In spite of the limitations mentioned above, there is plenty of pragmatic value in this full-scale, quantitative meta-analysis. First, Sirt1 was identified as a biomarker of overall survival in solid malignancies, especially in liver cancer and lung cancer. Second, we proposed that cytoplasmic rather than nuclear Sirt1 expression deserves more attention. Additional and more in-depth clinical studies are needed because current studies indicate that Sirt1 can serve as a more accurate prognostic predictor in carcinomas.

\section{MATERIALS AND METHODS}

\section{Search strategy}

We performed a thorough electronic search for relevant studies using PubMed and Web of Science that were published before December 2016. The search terms "Sirt1 AND (cancer OR neoplasm OR carcinoma OR malignancy)" were applied, and we initially identified 3474 studies for further examination. Both abstracts and full texts were elaborately screened to exclude irrelevant articles. Additionally, we reviewed the citation lists of the retrieved articles to guarantee the sensitivity of the search process. This procedure was carried out by two authors separately, and discrepancies were resolved by mutual discussions.

\section{Selection criteria}

Studies that met the following criteria were considered eligible and were included in our quantitative meta-analysis: (1) articles written in English and published before Dec. 2016; (2) studies discussing the correlation between Sirt1 expression and patient prognosis in human solid malignancies; (3) a minimal follow-up duration of 3 years; (4) a minimal sample-size of 10 participants; and (5) the diagnosis of solid malignancy was histologically and pathologically confirmed. Studies were excluded on the basis of the following criteria: (1) duplicate or overlapping populations; (2) lack of enough statistical data for further quantification analyses; (3) review articles or case reports; (4) animal studies; and (5) articles based on the Geo database. All evaluations were independently conducted by two authors to ensure the accuracy of the selection process.

\section{Data extraction}

General information, overall survival, cancerspecific survival, disease-free survival, and recurrencefree survival were extracted from qualified studies independently by two investigators. The original survival data for both comparative groups were calculated from the text, tables or Kaplan-Meier curves. The survival information from Kaplan-Meier curves were digitized and extracted using Enguage Digitizer 4.1. Any disagreements were resolved by mutual discussions. All extraction procedures were performed with the aid of predefined standardized extraction forms.

\section{Methodological quality assessment}

Newcastle-Ottawa Scale (NOS) [51] was applied for the quality evaluation of each selected article because all the eligible studies were observational studies. Certain adaptive modifications were made to revise the scale to match the practical needs of the analysis. The scale contained three categories including selection, comparability and outcome, and the maximum score was nine. Methodological high quality studies were those that scored more than six on this scale. The assessment process was conducted independently by two authors. 


\section{Statistical analysis}

All quantitative calculations were performed using Review Manager 5.3 (Cochrane Collaboration, Oxford, England). The hazard ratio (HR) at a $95 \%$ confidential interval (CI) was used to measure the correlation between Sirt1 expression and patient survival. The data, including the general survival analyses and sub-group comparisons, calculated from the articles were included in the form of generic inverse variables. Heterogeneity among studies was calculated using both the $I^{2}$ test and $Q$-test, and $I^{2}>25 \%$ or $P<0.05$ was defined as significant heterogeneity; therefore, a random-effects model (the DerSimonian and Laird method) was used. In all other cases, the fixed-effects model (Mantel-Haenszel method) was used. Additionally, we conducted a sensitivity analysis to test the consistency of the selected studies. Publication bias was determined using funnel plots, and $P<0.05$ signified a statistically significant publication bias. All $P$ values were 2-tailed.

\section{Abbreviations}

Sirt1 silent information regulator 1; OS overall survival; DFS disease-free survival; RFS relapse-free survival; CSS cancer-specific survival.

\section{Authors' contributions}

C.W. and S.R. contributed to the design of the study. C.W. contributed to the manuscript writing. C.W., W.Y., F.D., Y.G. and J.T. contributed to data extraction and analysis of the study. T.H. and S.R. contributed to the financial support and revision of the manuscript.

\section{ACKNOWLEDGMENTS}

We sincerely appreciate our lab members for providing methodological support for this publication.

\section{CONFLICTS OF INTEREST}

None.

\section{FUNDING}

This work was supported by the National Natural Science Foundation of China (grant no. 81001171) and the Key Technologies R\&D Program of Hubei Province (grant no. 2007AA302B07).

\section{REFERENCES}

1. Torre LA, Bray F, Siegel RL, Ferlay J, Lortet-Tieulent J, Jemal A. Global cancer statistics, 2012. CA Cancer J Clin. 2015; 65:87-108. doi: 10.3322/caac.21262.
2. Shen H, Laird PW. Interplay between the cancer genome and epigenome. Cell. 2013; 153:38-55. doi: 10.1016/j. cell.2013.03.008.

3. Saunders LR, Verdin E. Sirtuins: critical regulators at the crossroads between cancer and aging. Oncogene. 2007; 26:5489-504. doi: 10.1038/sj.onc.1210616.

4. Blander G, Guarente L. The Sir2 family of protein deacetylases. Annu Rev Biochem. 2004; 73:417-35. doi: 10.1146/annurev.biochem.73.011303.073651.

5. Yi YW, Kang HJ, Kim HJ, Kong Y, Brown ML, Bae I. Targeting mutant p53 by a SIRT1 activator YK-3237 inhibits the proliferation of triple-negative breast cancer cells. Oncotarget. 2013; 4:984-94. doi: 10.18632/ oncotarget.1070.

6. Choi HK, Cho KB, Phuong NT, Han CY, Han HK, Hien TT, Choi HS, Kang KW. SIRT1-mediated FoxO1 deacetylation is essential for multidrug resistance-associated protein 2 expression in tamoxifen-resistant breast cancer cells. Mol Pharm. 2013; 10:2517-27. doi: 10.1021/mp400287p.

7. Yeung F, Hoberg JE, Ramsey CS, Keller MD, Jones DR, Frye RA, Mayo MW. Modulation of NF-kappaBdependent transcription and cell survival by the SIRT1 deacetylase. EMBO J. 2004; 23:2369-80. doi: 10.1038/ sj.emboj. 7600244.

8. Taylor DM, Maxwell MM, Luthi-Carter R, Kazantsev AG. Biological and potential therapeutic roles of sirtuin deacetylases. Cell Mol Life Sci. 2008; 65:4000-18. doi: 10.1007/s00018-008-8357-y.

9. Jang KY, Kim KS, Hwang SH, Kwon KS, Kim KR, Park HS, Park BH, Chung MJ, Kang MJ, Lee DG, Moon WS. Expression and prognostic significance of SIRT1 in ovarian epithelial tumours. Pathology. 2009; 41:366-71. doi: 10.1080/00313020902884451.

10. Cha EJ, Noh SJ, Kwon KS, Kim CY, Park BH, Park HS, Lee H, Chung MJ, Kang MJ, Lee DG, Moon WS, Jang KY. Expression of DBC1 and SIRT1 is associated with poor prognosis of gastric carcinoma. Clin Cancer Res. 2009; 15:4453-9. doi: 10.1158/1078-0432.CCR-08-3329.

11. Wu M, Wei W, Xiao X, Guo J, Xie X, Li L, Kong Y, Lv N, Jia W, Zhang Y, Xie X. Expression of SIRT1 is associated with lymph node metastasis and poor prognosis in both operable triple-negative and non-triple-negative breast cancer. Med Oncol. 2012; 29:3240-9. doi: 10.1007/s12032012-0260-6.

12. Jung W, Hong KD, Jung WY, Lee E, Shin BK, Kim HK, Kim A, Kim BH. SIRT1 Expression Is Associated with Good Prognosis in Colorectal Cancer. Korean J Pathol. 2013; 47:332-9. doi: 10.4132/KoreanJPathol.2013.47.4.332.

13. Zhang WW, Luo JY, Yang F, Wang YC, Yin YM, Strom A, Gustafsson JA, Guan XX. BRCA1 inhibits AR-mediated proliferation of breast cancer cells through the activation of SIRT1. Scientific Reports. 2016; 6. doi: 10.1038/srep22034.

14. Chen XJ, Sun K, Jiao SF, Cai N, Zhao X, Zou HB, Xie YX, Wang ZS, Zhong M, Wei LX. High levels of SIRT1 expression enhance tumorigenesis and associate with a 
poor prognosis of colorectal carcinoma patients. Scientific Reports. 2014; 4. doi: 10.1038/srep07481.

15. Jang SH, Min KW, Paik SS, Jang KS. Loss of SIRT1 histone deacetylase expression associates with tumour progression in colorectal adenocarcinoma. J Clin Pathol. 2012; 65:735-9. doi: 10.1136/jclinpath-2012-200685.

16. Cheng F, Su L, Yao C, Liu L, Shen J, Liu C, Chen X, Luo Y, Jiang L, Shan J, Chen J, Zhu W, Shao J, et al. SIRT1 promotes epithelial-mesenchymal transition and metastasis in colorectal cancer by regulating Fra-1 expression. Cancer Lett. 2016; 375:274-83. doi: 10.1016/j.canlet.2016.03.010.

17. He Z, Yi J, Jin L, Pan B, Chen L, Song H. Overexpression of Sirtuin-1 is associated with poor clinical outcome in esophageal squamous cell carcinoma. Tumour Biol. 2016; 37:7139-48. doi: 10.1007/s13277-015-4459-y.

18. Jang KY, Noh SJ, Lehwald N, Tao GZ, Bellovin DI, Park HS, Moon WS, Felsher DW, Sylvester KG. SIRT1 and c-Myc promote liver tumor cell survival and predict poor survival of human hepatocellular carcinomas. PLoS One. 2012; 7:e45119. doi: 10.1371/journal.pone.0045119.

19. Zhang LH, Huang Q, Fan XS, Wu HY, Yang J, Feng AN. Clinicopathological significance of SIRT1 and p300/CBP expression in gastroesophageal junction (GEJ) cancer and the correlation with E-cadherin and MLH1. Pathol Res Pract. 2013; 209:611-7. doi: 10.1016/j.prp.2013.03.012.

20. Cao YW, Li WQ, Wan GX, Li YX, Du XM, Li YC, Li F. Correlation and prognostic value of SIRT1 and Notch1 signaling in breast cancer. J Exp Clin Cancer Res. 2014; 33:97. doi: 10.1186/s13046-014-0097-2.

21. Kang Y, Jung WY, Lee H, Lee E, Kim A, Kim BH. Expression of SIRT1 and DBC1 in Gastric Adenocarcinoma. Korean J Pathol. 2012; 46:523-31. doi: 10.4132/KoreanJPathol.2012.46.6.523.

22. Feng AN, Zhang LH, Fan XS, Huang Q, Ye Q, Wu HY, Yang J. Expression of SIRT1 in gastric cardiac cancer and its clinicopathologic significance. Int J Surg Pathol. 2011; 19:743-50. doi: 10.1177/1066896911412181.

23. Noguchi A, Kikuchi K, Zheng H, Takahashi H, Miyagi Y, Aoki I, Takano Y. SIRT1 expression is associated with a poor prognosis, whereas $\mathrm{DBC} 1$ is associated with favorable outcomes in gastric cancer. Cancer Med. 2014; 3:1553-61. doi: 10.1016/j.molcel.2014.07.011 10.1002/cam4.310.

24. Hao C, Zhu PX, Yang X, Han ZP, Jiang JH, Zong C, Zhang XG, Liu WT, Zhao QD, Fan TT, Zhang L, Wei LX. Overexpression of SIRT1 promotes metastasis through epithelial-mesenchymal transition in hepatocellular carcinoma. BMC Cancer. 2014; 14:978. doi: 10.1186/14712407-14-978.

25. Song S, Luo M, Song Y, Liu T, Zhang H, Xie Z. Prognostic role of SIRT1 in hepatocellular carcinoma. J Coll Physicians Surg Pak. 2014; 24:849-54. doi: 11.2014/jcpsp.849854.

26. Li YM, Xu SC, Li J, Zheng L, Feng M, Wang XY, Han KQ, Pi HF, Li M, Huang XB, You N, Tian YW, Zuo GH, et al.
SIRT1 facilitates hepatocellular carcinoma metastasis by promoting PGC-1 alpha-mediated mitochondrial biogenesis. Oncotarget. 2016; 7:29255-74. doi: 10.18632/ oncotarget.8711.

27. Chen HC, Jeng YM, Yuan RH, Hsu HC, Chen YL. SIRT1 promotes tumorigenesis and resistance to chemotherapy in hepatocellular carcinoma and its expression predicts poor prognosis. Ann Surg Oncol. 2012; 19:2011-9. doi: 10.1245/ s10434-011-2159-4.

28. Noguchi A, Li X, Kubota A, Kikuchi K, Kameda Y, Zheng H, Miyagi Y, Aoki I, Takano Y. SIRT1 expression is associated with good prognosis for head and neck squamous cell carcinoma patients. Oral Surg Oral Med Oral Pathol Oral Radiol. 2013; 115:385-92. doi: 10.1016/j. oooo.2012.12.013.

29. Chung YR, Kim H, Park SY, Park IA, Jang JJ, Choe JY, Jung YY, Im SA, Moon HG, Lee KH, Suh KJ, Kim TY, Noh DY, et al. Distinctive role of SIRT1 expression on tumor invasion and metastasis in breast cancer by molecular subtype. Hum Pathol. 2015; 46:1027-35. doi: 10.3978/j. issn.2304-3881.2014.08.06 10.1016/j.humpath.2015.03.015.

30. Yu XM, Liu Y, Jin T, Liu J, Wang J, Ma C, Pan XL. The Expression of SIRT1 and DBC1 in Laryngeal and Hypopharyngeal Carcinomas. Plos One. 2013; 8. doi: 10.1371/journal.pone.0066975.

31. Grbesa I, Pajares MJ, Martinez-Terroba E, Agorreta J, Mikecin AM, Larrayoz M, Idoate MA, Gall-Troselj K, Pio R, Montuenga LM. Expression of sirtuin 1 and 2 is associated with poor prognosis in non-small cell lung cancer patients. PLoS One. 2015; 10:e0124670. doi: 10.1371/ journal.pone.0124670.

32. Noh SJ, Baek HA, Park HS, Jang KY, Moon WS, Kang MJ, Lee DG, Kim MH, Lee JH, Chung MJ. Expression of SIRT1 and cortactin is associated with progression of nonsmall cell lung cancer. Pathol Res Pract. 2013; 209:365-70. doi: 10.1016/j.prp.2013.03.011.

33. Li C, Wang LL, Zheng L, Zhan XH, Xu B, Jiang JT, Wu CP. SIRT1 expression is associated with poor prognosis of lung adenocarcinoma. Oncotargets and Therapy. 2015; 8:977-84. doi: 10.2147/ott.s82378.

34. Shin DH, Choi YJ, Jin P, Yoon H, Chun YS, Shin HW, Kim JE, Park JW. Distinct effects of SIRT1 in cancer and stromal cells on tumor promotion. Oncotarget. 2016; 7:23975-87. doi: 10.18632/oncotarget.8073.

35. Lee H, Kim KR, Noh SJ, Park HS, Kwon KS, Park BH, Jung SH, Youn HJ, Lee BK, Chung MJ, Koh DH, Moon WS, Jang KY. Expression of DBC1 and SIRT1 is associated with poor prognosis for breast carcinoma. Hum Pathol. 2011; 42:204-13. doi: 10.1016/j.humpath.2010.05.023.

36. Mvunta DH, Miyamoto T, Asaka R, Yamada Y, Ando H, Higuchi S, Ida K, Kashima H, Shiozawa T. Overexpression of SIRT1 is Associated With Poor Outcomes in Patients With Ovarian Carcinoma. Appl Immunohistochem Mol Morphol. 2016; 25:415-421. doi: 10.1097/pai.0000000000000316. 
37. Stenzinger A, Endris V, Klauschen F, Sinn B, Lorenz K, Warth A, Goeppert B, Ehemann V, Muckenhuber A, Kamphues C, Bahra M, Neuhaus P, Weichert W. High SIRT1 expression is a negative prognosticator in pancreatic ductal adenocarcinoma. BMC Cancer. 2013; 13:450. doi: 10.1186/1471-2407-13-450.

38. Noh SJ, Kang MJ, Kim KM, Bae JS, Park HS, Moon WS, Chung MJ, Lee H, Lee DG, Jang KY. Acetylation status of P53 and the expression of DBC1, SIRT1, and androgen receptor are associated with survival in clear cell renal cell carcinoma patients. Pathology. 2013; 45:574-80. doi: 10.1097/PAT.0b013e3283652c7a.

39. Batra A, Kashyap S, Singh L, Bakhshi S. Sirtuin1 Expression and Correlation with Histopathological Features in Retinoblastoma. Ocular Oncology and Pathology. 2016; 2:86-90. doi: 10.1159/000439594.

40. Kim JR, Moon YJ, Kwon KS, Bae JS, Wagle S, Yu TK, Kim KM, Park HS, Lee JH, Moon WS, Lee H, Chung MJ, Jang KY. Expression of SIRT1 and DBC1 is associated with poor prognosis of soft tissue sarcomas. PLoS One. 2013; 8:e74738. doi: 10.1371/journal.pone.0074738.

41. Benard A, Goossens-Beumer IJ, van Hoesel AQ, Horati H, de Graaf W, Putter H, Zeestraten EC, Liefers GJ, van de Velde CJ, Kuppen PJ. Nuclear expression of histone deacetylases and their histone modifications predicts clinical outcome in colorectal cancer. Histopathology. 2015; 66:270-82. doi: 10.1111/his.12534.

42. Chung SY, Jung YY, Park IA, Kim H, Chung YR, Kim JY, Park SY, Im SA, Lee KH, Moon HG, Noh DY, Han W, Lee $\mathrm{C}$, et al. Oncogenic role of SIRT1 associated with tumor invasion, lymph node metastasis, and poor disease-free survival in triple negative breast cancer. Clin Exp Metastasis. 2016; 33:179-85. doi: 10.1007/s10585-015-9767-5.

43. Jin MS, Hyun CL, Park IA, Kim JY, Chung YR, Im SA, Lee KH, Moon HG, Ryu HS. SIRT1 induces tumor invasion by targeting epithelial mesenchymal transition-related pathway and is a prognostic marker in triple negative breast cancer. Chem Biol Drug Des. 2016; 37:4743-53. doi: 10.1111/cbdd. 12680 10.1007/s13277-015-4231-3.
44. Wu MQ, Wei WD, Xiao XS, Guo JL, Xie XH, Li LS, Kong YN, Lv N, Jia WH, Zhang Y, Xie XM. Expression of SIRT1 is associated with lymph node metastasis and poor prognosis in both operable triple-negative and non-triplenegative breast cancer. Medical Oncology. 2012; 29:3240-9. doi: 10.1007/s12032-012-0260-6.

45. Gharabaghi MA. Diagnostic investigation of BIRC6 and SIRT1 protein expression level as potential prognostic biomarkers in patients with non-small cell lung cancer. Clin Respir J. 2016 Oct 21. doi: 10.1111/crj.12572. [Epub ahead of print].

46. Derr RS, van Hoesel AQ, Benard A, Goossens-Beumer IJ, Sajet A, Dekker-Ensink NG, de Kruijf EM, Bastiaannet E, Smit VT, van de Velde CJ, Kuppen PJ. High nuclear expression levels of histone-modifying enzymes LSD1, HDAC2 and SIRT1 in tumor cells correlate with decreased survival and increased relapse in breast cancer patients. BMC Cancer. 2014; 14:604. doi: 10.1242/dev.110627 10.1186/1471-2407-14-604.

47. Song NY, Surh YJ. Janus-faced role of SIRT1 in tumorigenesis. Ann N Y Acad Sci. 2012; 1271:10-9. doi: 10.1111/j.1749-6632.2012.06762.x.

48. Tanno M, Sakamoto J, Miura T, Shimamoto K, Horio Y. Nucleocytoplasmic shuttling of the NAD+-dependent histone deacetylase SIRT1. J Biol Chem. 2007; 282:6823-32. doi: 10.1074/jbc.M609554200.

49. Cao YW, Li YC, Wan GX, Du XM, Li F. Clinicopathological and prognostic role of SIRT1 in breast cancer patients: a meta-analysis. Int J Clin Exp Med. 2015; 8:616-24.

50. Jiang B, Chen JH, Yuan WZ, Ji JT, Liu ZY, Wu L, Tang Q, Shu XG. Prognostic and clinical value of Sirt1 expression in gastric cancer: A systematic meta-analysis. J Huazhong Univ Sci Technolog Med Sci. 2016; 36:278-84. doi: 10.1007/s11596-016-1580-0.

51. Stang A. Critical evaluation of the Newcastle-Ottawa scale for the assessment of the quality of nonrandomized studies in meta-analyses. Eur J Epidemiol. 2010; 25:603-5. doi: 10.1007/s10654-010-9491-z. 